\title{
The opinion podcast: A visceral form of persuasion
}

\author{
Alison Klein* \\ $2 / 3 / 2020^{\dagger}$
}

\begin{abstract}
In this assignment, students create a podcast episode in which they make an argument on a topic in current events. Through this process, students develop traditional rhetorical skills such as awareness of audience, formulation of a thesis, and inclusion of compelling evidence, in a new context that allows them room for creativity and for approaching these techniques from a different angle. Accustomed to composing analysis essays and research papers on a computer screen, students who create an argument in the aural medium must consider the best way to grab and hold the listener's attention so that the listener's mind does not wander, and to convey information clearly and concisely so that the listener never needs to rewind. Additionally, students become familiar with audio editing software and other aspects of digital composition, and they explore a medium that may feel like a refuge in today's screen-saturated world.
\end{abstract}

All first-year students at my institution are required to take Writing 101, Academic Writing. My Writing 101 class, The Popularity of Podcasts, is themed around podcasting in part because of the explosive popularity of this medium: the first season of Serial reached 10 million downloads in seven weeks, and in 2018, 26\% of Americans listened to a podcast monthly, up from $9 \%$ in 2008 (Edison Research, 2019). More importantly for an academic writing course, podcasts have great potential for analysis and modeling, as the extensive range of topics, styles, and formats allows for rich discussions of purpose, genre conventions, tone, and other aspects of composition.

In the assignment presented here, the second major assignment of the course, students craft their own arguments in an opinion-based podcast episode, modeled after professional podcasts that intend to persuade. Persuasion may initially seem an unusual direction for a podcast assignment: many of the most popular podcasts are intended to entertain

\footnotetext{
${ }^{*}$ Duke University, alison.klein@duke.edu. Copyright 2020 Alison Klein. This work is licensed under a Creative Commons Attribution-NonCommercial 4.0 International License (http://creativecommons.org/licenses/by-nc/4.0/).

${ }^{\dagger}$ Submitted, 4/8/2019; Accepted, 11/2/2019.
} 
or inform through story-telling, and the critical conversation around podcasts often focuses on narrative-driven shows like Serial and The Memory Palace. For example, in Out on the Wire, a graphic exploration of radio and podcasts, Jessica Abel (2015) explains her attraction to the aural medium: "Radio, especially public radio and the podcasts that have sprung from it... is the most fertile ground for narrative non-fiction in English-language media" (p. 2). Yet podcasts present equally fertile ground for argument. Politically-oriented shows such as the highly popular Pod Save America and The Ben Shapiro Show attempt to convince the listener to accept the host's perspective or take action on an issue. Other podcasts that are not explicitly argument-based often include episodes with a persuasive bent. For instance, Malcolm Gladwell's primarily informative podcast Revisionist History explores events from the past from a new perspective, but in his episode "Food Fight" (2017), he compares the financial aid systems at Bowdoin and Vassar and concludes that educational institutions should prioritize financial aid over amenities such as cafeteria food and gymnasiums.

The educational applications of such podcasts have been underexplored. Analyzing and assessing the claims of professional podcasters encourages students to apply their critical thinking skills across a variety of mediums and modes. By then creating their own podcast episode in which they put forth and support a thesis in a format that may be less familiar to them, students reconsider the best way to formulate arguments and explore their creativity, finding original and engaging ways to capture their audience's attention. In this medium, rhetorical skills that may otherwise seem abstract, such as awareness of one's audience, become immediately relevant and visceral. When composing on a computer, one often feels removed from the reader who will someday see those words on a page or a screen. On the other hand, when one imagines an audience listening to the sound of one's voice, the intimacy of this act highlights the importance of keeping the prose clear and engaging, and of targeting the evidence at the intended audience. Similarly, Deborah Justice (2018), writing about an assignment in which students in her Music and Sports course recorded spoken responses to a prompt, observes: "The aural nature of this set of assignments allowed students to think about writing as an interactive engagement, rather than dry words on a page" (p. 63). Including an aural assignment can thus be a useful way of making composition an interactive process in a wide range of classes.

When designing the course, I drew on the curriculum of Denise Comer, whose academic writing class was themed Podcasts and Popular Scholarship, and the syllabi of Matt Cunningham and Jill Geisler's course Podcasting: Digital Storytelling (2017) and Audrey Quinn's NYU Documentary Storytelling for Radio and Podcasts (2016). (At the time of writing, the latter two syllabi were available online, though Comer's was not.) I also was inspired by Jeremy Cushman and Shannon Kelly's chapter in Soundwriting Pedagogies (n.d.), in which they describe a podcast assignment included in all first-year writing classes at their institution. Their chapter focuses on the challenges that students and the Graduate Teaching Assistants (GTAs) faced in implementing the assignment, such as the difficulty of grading an assignment that felt so personal. Cushman and Kelly conclude 
that in spite of the challenges of teaching a podcast, by speaking their compositions, the students embodied their work in a way that is impossible to do when composing for reading, making them more active participants in the composing process and creating a visceral experience similar to the one I saw in my own students. Their points about both the challenges and rewards of a podcast assignment resonate with me, and the authors include many useful resources, such as examples of podcasts that students created. Each of these courses, however, focuses on narrative-driven podcasts, whereas I wanted my students to develop an argument within the oral medium.

Jennifer L. Bowie's work on the benefits (and downsides) of including podcasts in the classroom includes the only example I have seen of a persuasion-oriented podcast project. Bowie describes an assignment she created called a "Media Analysis Project" (2012a) in which students crafted an argument, first in written form and then in podcast form, and then reflected on the differences between the two. Her assignment is a fascinating one, but again, the focus is somewhat different from what I wanted to achieve. Her project emphasizes the comparison between the two modes and also places more weight on sound editing, while my primary goal was to teach students how to develop an argument, and I found podcasting to be an effective way to do so. Additionally, the classes in which she incorporated podcast episodes were upper-level rhetoric courses that focused specifically on podcasts or electronic composition; I argue that a student-created podcast episode can be integrated into any writing-focused class. ${ }^{1}$

Finally, I am grateful to the podcast professionals who shared their wisdom with me through email, phone, and in-person conversations. Lulu Miller of Invisibilia pointed me to helpful texts, such as Ira Glass's interview in Transom (2004), in which he gives tips for producing strong audio, and she also offered examples of podcasts that break Glass's guidelines. Lauren Spohrer of Criminal gave practical advice on conducting effective interviews and structuring podcasts, and Sam Dingman of Family Ghosts shared his insights about developing an authentic voice.

My course focuses on podcasts broadly, and it is not until the second assignment that we home in on persuasion. At the beginning of the course, we discuss Sarah Montague's "Towards a Poetics of Audio" (2017), in which she calls for the development of a body of scholarship on podcasts. Building on this discussion, students create a list of the elements that one might focus on when analyzing podcasts, since there is no such agreed-upon list as there might be when analyzing a film or a short story. The lists they produce include elements such as host narration, interviews, and music, and we then brainstorm questions that one could ask when analyzing those elements in a specific podcast episode. In the first major assignment of the course, students draw on the elements and questions that they developed to analyze a podcast episode of their choice and evaluate its effectiveness. Since there are podcasts on every conceivable topic, it is easy for students to find one relating to their interests, and so they are highly engaged in this analysis. Further, the cutting-edge nature of this content, in which students experience the excitement of crafting the field themselves, is one of the major benefits of including podcasts in an academic course. While podcasts themselves have been around for fifteen years, there 
is relatively little critical analysis of the genre, and one would be hard-pressed to find an accepted list of, say, the elements of podcasts in the same way that there are fairly standard lists of the elements of film, poetry, and painting.

In the assignment prompt given here, the Opinion Podcast, students apply what they learned about effective podcasting to craft their own podcast episode in which they take a position on a topic in current events. The choice of topic is again theirs, so that they can focus on an issue they find engaging. Their episode must include an introduction, an interview (or portions of an interview), and a conclusion. When grading their podcasts, I am looking for a clear thesis, supporting points, and evidence for their arguments, such as statistics or narrative anecdotes. As I explain to my students, the goals of the assignment are to form compelling arguments, develop written and oral communication skills, experiment with technology and multi-modal composition, and become more aware of audience. This last is a central concern of this assignment: as noted earlier, the podcast form, in which the author speaks directly to the listener, makes clear the importance of considering to whom you are targeting your piece, and the opinion-based podcast episode in particular highlights this concern. For example, if one were arguing that smoking should be banned on campus, the evidence, tone, and diction would differ if directing the podcast at other students rather than the president of the university.

The entire assignment takes four weeks out of the fourteen-week semester. In the first week, we listen to professional examples of opinion-based podcasts, podcasts that put forward an argument rather than telling a story or offering advice. For example, we listen to Malcolm Gladwell's aforementioned episode "Food Fight," in which he argues that colleges and universities have an obligation to spend less money on amenities such as dining halls and more money on financial aid. I also choose a controversial topic in current events and find two podcasts that consider that topic from different perspectives. For instance, when I taught the course in 2017, we listened to two podcasts that addressed President Trump's ban on foreign nationals from seven predominantly Muslim nations entering the country. \#GoodMuslimBadMuslim (2017) challenged the ban, comparing it to anti-Japanese legislation that preceded the creation of Japanese internment camps during World War II, while The Renegade Republican (2017) argued that the ban was a continuation of previously existing legislation and necessary for the safety of the country.

These episodes demonstrate the immediate relevance that such pieces can have. Additionally, we use these episodes as models, discussing which episode makes a more compelling case and what elements of that episode contribute to or detract from its effectiveness. For example, we consider whether the interviews are unbiased, whether factual evidence has been presented in a clear and ethical way, and whether the host has addressed the opposing view. We also dissect how their techniques differ from authors crafting written arguments, focusing on aspects such as repetition of points, simplification of information, and the host's tone. We return to the issue of audience, discussing whether the episodes are aimed at those who agree with the host or those who disagree, and how that impacts the overall effectiveness of the piece. 
Building on these conversations, we then brainstorm potential topics that students could use in their podcasts, looking for issues at the local, regional, and national level. At the local level, for example, students have suggested the campus ban on straws; at the regional level, what should be done with confederate monuments; and at the national level, the U.S. withdrawal from the Paris climate accords. Students then develop a pitch for their podcast, which includes the topic, target audience, and tentative thesis of their podcast, as well as why others would find the topic interesting. I encourage them to look at the pitch guidelines and examples on the This American Life website for guidance. They post their pitch on a blog, and other students respond, identifying aspects of the pitch that they found compelling and potential directions for the episode or suggestions for improvement.

In the second week, students choose an interview subject and send out a request, then create a list of questions for the interview. I encourage students to pick an interviewee who is connected to the university, such as a professor who is an expert on the topic of the episode or an administrator who deals first-hand with the central issue of the episode. This makes it easier to set up an interview in a short amount of time and to conduct that interview in person, which in turn leads to better sound quality. At my institution, students can borrow microphones and other recording equipment from the multi-media lab, but computer- and phone-recorded interviews also work well. To prepare for the interview, students read an excerpt on interview techniques from Out on the Wire (Abel, 2015), which offers many practical tips for would-be radio or podcaster creators. We also discuss effective ways to develop and organize questions, such as identifying possible follow-up questions and saving contentious questions for last.

Students also develop a story board this week, a layout of what they plan to say and the timing within their episode. (See supplemental materials for a storyboard template example.) In the third week, we focus on the script of the podcast. I break students into groups and assign them one of the episodes that we have already discussed. Analyzing the transcript of the episode (transcripts are usually available for podcasts that are supported by radio stations and other major media outlets), students identify what is and is not successful in the intro and outro of the piece, considering aspects such as the use of a teaser in the intro and circling back to that teaser in the outro. After discussing their findings, students begin drafting their own script, which they complete for homework. Over the weekend, they record the rough draft of their episode. In the final week, students workshop each other's episodes, then edit them into a final product, rerecording segments as needed.

Students receive feedback at every stage of the process. They peer edit each other's interview questions and storyboards, respond to each other's pitches, and listen to, comment on, and discuss the episode rough drafts. I also conference with each of them about their pitches and comment on their rough drafts. This level of intervention and feedback makes it possible to complete the assignment in a relatively short amount of time, as the students require less time to work out their ideas or tinker with the structure of their podcast episodes. Once the students have completed their episodes, I upload them 
to PodBean, a free podcast hosting website, and so they are able to share their episodes with their friends and family. ${ }^{2}$ Their work can be found here and here. I considered using a blog-oriented site such as Blogger or WordPress, but PodBean, designed specifically for podcasts, includes an easy-to-use upload tool and presents the episodes in a clear and user-friendly way. The main downside is that you can only present ten episodes per page, so if your class has more than ten students, some episodes will appear on subsequent pages.

In the third and final assignment of the course, students write a research paper about a controversial issue in podcast studies. Having completed the Opinion Podcast, they are now well-prepared for this assignment. They have sharpened their skills of formulating arguments, engaging their audience, and structuring their points. I have found that after creating their own podcast episode, students are more likely to include sign-posting, clear connections between ideas, and other techniques of effective composition in their written work. Further, they can draw on their first-hand experience of making a podcast episode within their argument. For instance, a non-native speaker in my class wrote her research paper on biases against hosts and guests with accents, and she began her discussion with an engaging description of her own experience of podcasting.

Each time that I have taught the Opinion Podcast, the students have met and surpassed my goals. They form compelling arguments, such as the student who argued that the women's basketball team should receive as much funding as the men's. They demonstrate great creativity: one student began his podcast with the sound of pouring a cup of coffee in order to draw attention to the many legal drugs that are already a part of our daily life and build his case that marijuana should be legalized. They also show a strong awareness of audience, such as the student who argued that the university should raise the standard air conditioning temperature in campus buildings from 67 to 72 degrees. She directed her points at the administration, noting that this move would save money, give the university a stronger reputation for being green, and make students more productive. Finally, they develop stronger written and oral language skills. Throughout the semester, I encourage my students to read their work out loud in order to catch mistakes, and creating a podcast forces them to do just that and reinforces the importance of hearing one's work, even if the final product is a written text. They also sharpen their ability to speak in an engaging and effective way, which will serve them well when giving presentations or speeches or during employment interviews. Even students who initially expressed concern about recording their own voices ultimately found the podcast to be a useful exercise. One noted that this assignment helped him recognize and curtail his tendency to speak in a monotone, while the non-native speaker described above reported that she felt more confident with public speaking after recording her episode. In course evaluations at the end of the semester, several students expressed that this was one of their favorite assignments, and one student was even inspired to join the campus podcast after completing this assignment.

The major challenge of this assignment is that it requires access to and the ability to use technology. While all of my students have had laptop computers and access to audio 
editing software, many report difficulties in mastering the software, and one accidentally erased an entire interview. For the most part, though, they learn the software well enough to produce effective podcasts, and one student found a workaround by recording his entire podcast in one take, and then rerecording it, interview and all, for the final draft. I had mixed feelings about this choice; I did want students to learn editing software, but this was not the main goal of the assignment and was not explicitly required. Additionally, the student revealed to me that it took him several takes to get a workable recording, and so he certainly polished his presentation style and probably spent as much time and effort as he would have if he had edited the piece.

I am fortunate in that my institution has a multi-media lab, where I send students who have questions beyond my basic understanding of audio editing applications, but the students themselves made a suggestion that might address this need at an institution without such a resource. The last time we completed this assignment, I asked students for feedback, and one suggested that I dedicate some class time to troubleshooting, where they could discuss the challenges they experienced with the software and share the tricks that they had learned. When I teach this assignment in the future, I plan to set aside time for this between the rough draft and the final draft.

I teach at a private, $\mathrm{R} 1$ institution, and I recognize that the institutional and personal resources available to my students make this assignment viable. In addition to having the support of the multi-media lab, I can expect my students to have laptop computers and to be fairly tech-savvy. While these conditions may not be the same at all institutions, some modified version of this assignment might still be possible. Most smartphones have recording and editing capabilities, so students could create a podcast episode on their phone.

Another difficulty of this assignment is finding the right amount of time to dedicate to it. Most of the classes that incorporate podcasts do so over the course of the semester, and so students have months to learn the technology. Some students in my course reported frustration at not having time to fully master the software, yet they also expressed that their enjoyment in creating their episodes was well worth the frustration. On the other hand, even the amount of time that I take for this assignment might seem too much in a content-heavy class. Since my class is themed around podcasts, we have already listened to and analyzed several professional podcasts by the time we get to the Opinion Podcast, which might be difficult for a class that is not focused on writing or has a different theme. A possible solution might be to listen to podcasts related to course topics throughout the course and include the podcast as a final assignment.

In addition to encouraging students to develop creative and technological skills, podcasts are relatively easy to create and disseminate, making them a highly democratizing medium. Some popular culture critics have even argued that podcasts include all the best parts of the internet with none of the worst, since they do not encourage screen addiction or distance us from others. Cultural critic Jonah Weiner argues, "podcasts are the Internet freed from pixels" (2014). In today's screen-saturated world, students who 
are encouraged to explore podcasts might find them to be a refuge of a kind. By creating an opinion-based podcast, students are developing the skills to evaluate the arguments of others and formulate their own arguments in a medium that may provide that refuge.

\section{Assignment: Opinion Podcast}

(To view a PDF facsimile of the original formatting of this assignment, return to this article's homepage and locate the link to the "Assignment" PDF.)

Introduction:

In the previous assignment, the Podcast Analysis, you considered what makes effective communication, exploring one podcast episode in detail to identify techniques to engage your audience. In this assignment, you will be applying those techniques to your own communication.

You will create your own 8-10 minute podcast in which you put forth an argument on a topic of your choice.

Your episode should include three segments: an introduction, a central section that contains at least one interview, and a wrap up. When you upload your podcast, you should also upload a Works Cited in Word that includes any sources that you used for information as well as any music or other sound material that you did not develop yourself.

Purpose:

The goal of this assignment is to help you develop a persuasive argument, consider what evidence might sway your audience most effectively, and apply the techniques that you found to be successful in the podcast that you analyzed (while avoiding the ones you found less successful). For example, do you want to use humor to address a potentially tense issue? Give brief anecdotes to bring your points to life? And so on. Every academic discipline requires the development of an effective argument, not to mention the many times that we use persuasion in day-to-day life, and so these are skills that will be useful to you whatever path you may take. I also hope that you will enjoy the production of the podcast itself as a creative outlet for your ideas.

Deadlines:

- The rough draft of your podcast is due by $8 \mathrm{PM}$ the night before Class Day 1, to be submitted on Sakai. The structure of peer editing will be different for this assignment, since it would be difficult to listen to the episodes in class. You will listen to the podcasts of your workshop group by class time on Class Day 1, and you will workshop your podcast in class that Friday.

- On Class Day 2, I will give you individual feedback, and we will discuss general patterns and issues. 
- The final version of your podcast, along with a revision reflection, is due on Sakai on Class Day 3.

Writing Process:

Step 1: Picking your topic

Your first task is to identify a topic. For example, you might decide to focus on whether college athletes should be paid, or the issue of climate change. You may respond to one of the podcasts that we have listened to or one of the articles that we have read, but that is not required. Try to choose a topic that is important to you - remember that if you are interested in your topic, it is much more likely that your audience will be, too. Keep in mind, too, that your peers will be listening to your podcast. While you are welcome to choose topics that others might disagree with, please address opposing views in a respectful manner and avoid hurtful or inflammatory language.

\section{Step 2: Developing your argument}

Next, you need to come up with a thesis, an argument that you are making about your topic that reasonable people could disagree with. Your argument should be specific enough that you can explore it in a 10-minute podcast. For example, you might argue that college athletes should be paid because they bring prestige to the university, or that climate change is the single greatest threat to biodiversity.

\section{Step 3: Gathering evidence}

Your evidence might come in the form of statistics, anecdotes, and analogies, but you should include at least one interview. This could be an interview with an expert, or with someone affected by this issue, or even someone who has the opposing view, as long as you treat their viewpoint (and them) with respect. For example, if you are writing about college athletes, you could interview athletes at Duke. If you are writing about climate change and biodiversity, you could track down a biology professor who works on this topic. We will discuss techniques for conducting an ethical interview, but please make certain that your interviewees understand that they are being recorded and have given consent. Interviews are easier to record than you might think - most laptops and smart phones have recording capability. For a more professional sound, you can borrow mics and other recording equipment from Duke Link.

\section{Step 4: Planning your podcast}

Once you have gathered evidence, you should plan out your podcast, identifying the order and amount of time you would like to devote to each element, as well as any background music, sound effects, and interviews, etc. that you would like to include. We will work on storyboards together, and remember to consult the planning guides that we discussed in class. We will also work together on drafting the narration for your podcast - the script for what you will say as a frame for your material. As you work through these steps, think about the aspects of the episodes that we have listened to that worked well to engage the audience, as well as any issues that detracted from those episodes. 


\section{Step 5: Recording and editing your podcast}

If you have a Mac, you should already have the application GarageBand, which you can use to create your podcast. Here is a link to a video tutorial on creating a podcast with GarageBand. If you have a PC, you can download Audacity, a free application. Here is a text guide for creating a podcast with Audacity, and here is a video tutorial for Audacity. You can find more tutorials for either program through YouTube or through Google Searches. Additionally, as a Duke student, you have access to online training through Lynda for many programs, GarageBand and Audacity included. Finally, the Multimedia Project Studio, located in Room 006 in Bostock Library, is a wonderful space where you can access high-end editing software and ask trained consultants questions about GarageBand, Audacity, or other applications.

You are welcome to use material from other sources - news, other podcasts, movies, etc., as long as you cite them. Technically, you should be able to use any of these materials as long as it is for academic purposes (rather than financial gain), but if you are interested in finding music that is available for public use, try searching on Google for "royalty free music."

Grading:

Please see the attached rubric for grading. I will be considering the content of your podcast - the strength of the argument that you are making and the evidence that you include, but also your delivery and the production of your podcast - transitions between segments, quality of audio, engaging presentation, etc. That said, I do not expect you to become experts at podcast creation within the weeks that we are working on this assignment, and I will certainly allow for some roughness in your episodes.

To conclude:

Have fun! I hope that you develop a deeper understanding of the topic of your choosing, but also that you get creative with your podcast. I look forward to hearing them, and I'm sure your peers are looking forward to hearing them, too!

\section{Notes}

\footnotetext{
${ }^{1}$ See also, among others, Krause (2006) for an early examination of the benefits of including teacherproduced podcasts in the classroom, Forbes (2011) for a summary of the ways that student-produced podcasts increase metacognitive reflection, Bowie (2012b) for an in-depth exploration of the rhetorical skills that student-produced podcasts can help develop, and Detweiler (2018) for an argument in favor of rhetorical scholarship both about and in the audio genre.

${ }^{2}$ Not all students feel comfortable sharing their podcasts online, and so I let them decide what they will share publicly. All students create an iTunes-style entry that includes the title of the podcast and episode, the logo of the podcast, an episode summary, and the MP3 file of the episode. However, they choose how much of that information I upload to PodBean.
} 


\section{References}

Abel, J. (2015). Out on the wire: The storytelling secrets of the new masters of radio. New York, NY: Broadway Books.

Ahmed, T., \& Noorbakhsh, Z. (2017, May 27). Manzanar pilgrimage. \#GoodMuslimBadMuslim. Retrieved from http://www.goodmuslimbadmuslim.com/podcast/2017/5/ 27/029-manzanar-pilgrimage

Bongino, D. (2017, January 30). The media is lying to you AGAIN, there's NO Muslim ban. The Renegade Republican. Retrieved from https://soundcloud.com/dan-bongino/ep384-the-media-is-lying-to

Bowie, J. L. (2012a). Podcasting in a writing class? Considering the possibilities. Kairos: A Journal of Rhetoric, Technology, and Pedagogy, 11(2). Retrieved from http://kairos.technorhetoric.net/16.2/praxis/bowie/index.html

Bowie, J. L. (2012b). Rhetorical roots and media future: How podcasting fits into the computers and writing classroom. Kairos: A Journal of Rhetoric, Technology, and Pedagogy, 11(2). Retrieved from http://kairos.technorhetoric.net/16.2/topoi/bowie/ index.html

Cushman, J., \& Kelly, S. (n.d.). Recasting writing, voicing bodies: Podcasts across a writing program. In C. Danforth, K. Stedman, \& M. Faris (Eds.), Soundwriting pedagogies. Logan, UT: Computers and Composition Digital Press/Utah State University Press. Retrieved from http://ccdigitalpress.org/soundwriting

Detweiler, E. (2018). A podcast?! Whatever gave you that idea? Some reverberations from Walter Benjamin's radio plays. In J. Rice, C. Graham, \& E. Detweiler (Eds.), Rhetorics change/rhetoric's change (pp. 73-102). Intermezzo and Parlor Press. Retrieved from http://intermezzo.enculturation.net/07-rsa-2016-proceedings.htm

Edison Research. (2019). The podcast consumer 2018. Retrieved from https:// www.edisonresearch.com/podcast-consumer-2018/

Forbes, D. (2011). Beyond lecture capture: Student-generated podcasts in teacher education. Waikato Journal of Education, 16(1). Retrieved from https://wje.org.nz/ index.php/WJE/article/view/70

Gladwell, M. (2017, July 9). Food fight. Revisionist history. Retrieved from https://blog.simonsays.ai/food-fight-with-malcolm-gladwell-e5-s1-revisionist-historypodcast-transcript-113601722d87

Glass, I. (2004, June 1). Ira Glass's manifesto, part one. Retrieved from https:// transom.org/2004/ira-glass/ 
Justice, D. (2018). Music, Sports, and the Sound of Writing. Prompt: A Journal of Academic Writing Assignments, 2(2), 58-64.

Krause, S. D. (2006). Broadcast composition: Using audio files and podcasts in an online writing course. Computers and Composition Online.

Loyola University College. (2017). Podcasting: Digital storytelling [Course syllabus]: Matt Cunningham and Jill Geisler. Retrieved from https://www.luc.edu/media/lucedu/ soc/pdfs/coursesyllabi/spring2017/COMM_372-202_JGeisler_MCunningham.pdf

Montague, S. (2017). Towards a poetics of audio: The importance of criticism. Retrieved from http://thesarahawards.com/article/2017/4/3/towards-a-poetics-of-audiothe-importance-of-criticism

New York University. (2016). Syllabus - documentary storytelling for radio and podcasts: Audrey Quinn. Retrieved from https://journalism.nyu.edu/wp-content/uploads/quinnaudio-course-syllabus-9_6_16.pdf

Weiner, J. (2014, December 14). Towards a critical theory of podcasting. Slate. Retrieved from http://www.slate.com/articles/arts/ten_years_in_your_ears/2014/12/ what_makes_podcasts_so_addictive_and_pleasurable.html 